Res., Soc. Dev. 2019; 8(6):e23861049

ISSN 2525-3409 | DOI: http://dx.doi.org/10.33448/rsd-v8i6.1049

\title{
Produção de subjetividades e convivência escolar
}

Production of subjectivities and school coexistence

Producción de subjetividades y convivencia escolar

Recebido: 14/03/2019 | Revisado: 15/03/2019 | Aceito: 26/03/2019 | Publicado: 29/03/2019

Elysangela Koglin Ulo Limachi

ORCID: https://orcid.org/0000-0002-6085-5292

Universidade Franciscana, Brasil

E-mail: pselysangela@gmail.com

Isabelle Rittes Nass

ORCID: https://orcid.org/0000-0001-5444-9709

Universidade Franciscana, Brasil

E-mail: isabellernass@gmail.com

Marcele Pereira da Rosa Zucolotto

ORCID: https://orcid.org/0000-0002-6856-8626

Universidade Franciscana, Brasil

E-mail: marcelepr@hotmail.com

\section{Resumo}

Este artigo tem como objetivo apresentar os resultados de um estudo que buscou problematizar a questão da convivência escolar a partir da perspectiva da construção da subjetividade. Para tanto, foi realizada uma pesquisa bibliográfica a respeito do conceito de subjetividade, buscando possibilidades para ampliar a reflexão sobre a convivência escolar. Assim, por meio de uma breve contextualização histórica a respeito dos processos de construção de subjetividades e da instituição escolar tal como conhecemos, foi possível entender que esta se configura como um espaço não somente de transmissão de conhecimentos objetivos a partir das disciplinas, mas também como um local de socialização no qual todos os sujeitos envolvidos são subjetivados. Pôde-se perceber que a fragmentação da escola impede o desenvolvimento de uma percepção global acarretando um aumento no grau de angústia, solidão, isolamento e consumismo, fatores característicos da subjetividade denominada capitalística. Em decorrência da fragilidade das relações, na convivência escolar, são frequentes ações de exclusão, desrespeito e resistência. Portanto, a necessidade de pensar 
na convivência democrática se torna fundamental para a construção de sujeitos ativos e cada vez mais capazes de levar em conta os valores da coletividade.

Palavras-chave: Processos de Subjetivação; Escola; Convívio.

\begin{abstract}
This article aims to present the results of a study that sought to problematize the issue of school coexistence from the perspective of the construction of subjectivity. For that, a bibliographical research was carried out regarding the concept of subjectivity, looking for possibilities to broaden the reflection about the school coexistence. Thus, through a brief historical contextualization about the processes of construction of subjectivities and the school institution as we know it, it was possible to understand that this is configured as a space not only for transmitting objective knowledge from the disciplines, but also as a place of socialization in which all the subjects involved are subjectivated. It can be seen that the fragmentation of the school prevents the development of a global perception, leading to an increase in the degree of anguish, loneliness, isolation and consumerism, characteristic factors of subjectivity called capitalism. As a result of the fragility of the relationships, in school coexistence, there are frequent actions of exclusion, disrespect and resistance. Therefore, the need to think about democratic coexistence becomes fundamental for the construction of active subjects and increasingly able to take into account the values of the collectivity.
\end{abstract}

Keywords: Subjectivation processes; School; Conviviality.

\title{
Resumen
}

Este artículo tiene como objetivo presentar los resultados de un estudio que buscó problematizar la cuestión de la convivencia escolar desde la perspectiva de la construcción de la subjetividad. Para ello, se realizó una investigación bibliográfica acerca del concepto de subjetividad, buscando posibilidades para ampliar la reflexión sobre la convivencia escolar. Así, por medio de una breve contextualización histórica acerca de los procesos de construcción de subjetividades y de la institución escolar tal como conocemos, fue posible entender que ésta se configura como un espacio no sólo de transmisión de conocimientos objetivos a partir de las disciplinas, sino también como un lugar de socialización en el cual todos los sujetos involucrados son subjetivados. Se pudo percibir que la fragmentación de la escuela impide el desarrollo de una percepción global acarreando un aumento en el grado de angustia, soledad, aislamiento y consumismo, factores característicos de la subjetividad denominada capitalística. En consecuencia de la fragilidad de las relaciones, en la convivencia 
escolar, son frecuentes acciones de exclusión, falta de respeto y resistencia. Por lo tanto, la necesidad de pensar en la convivencia democrática se vuelve fundamental para la construcción de sujetos activos y cada vez más capaces de tener en cuenta los valores de la colectividad.

Palabras clave: Procesos de Subjetivación; la escuela; Convivencia.

\section{Introdução}

O contexto escolar é, por assim dizer, um espaço de construções e desconstruções. Espaço este onde cada sujeito se insere (ou é inserido?) buscando expandir suas relações e adquirir o tão desejado conhecimento para libertar-se da ignorância e estabelecer-se como cidadão autônomo, independente e livre. Este pelo menos parece ser o plano. No entanto, a escola como instituição social por vezes desenvolve papéis antagônicos; ao mesmo tempo em que deseja preparar o sujeito para a vida em sociedade, isola-se dentro de seus muros a fim de proteger os seus (alunos, principalmente) das más influências desta mesma sociedade na qual se encontra. E ainda, por vezes, desenvolve o papel de ensinar e perpetuar os valores sociais vigentes no momento (Bock, Furtado \& Teixeira, 2008).

Diante desse panorama, é preciso considerar os atores envolvidos nesses diferentes processos de ensinar, aprender, socializar e educar: alunos, professores, gestores e funcionários. Todos são responsáveis pelas ações e relações que se estabelecem no meio escolar, compreendendo que todos são sujeitos que se constroem mutuamente em suas relações. Dentro deste contexto (e mesmo fora), são ensinados valores que constroem subjetividades, que constroem modos de vida, que influenciarão nos posicionamentos, atitudes e comportamentos, que, portanto, repercutirão na convivência social como um todo (Bock, Furtado \& Teixeira, 2008; Mosé, 2015).

Em face do exposto, entende-se que a educação escolar abrange a transformação tanto intelectual quanto existencial dos sujeitos envolvidos. Neste caminho reflexivo, Eizirik e Comerlato (2004), pensando sobre como circulam as relações no contexto escolar, bem como sobre a produção de subjetividades que ali se dão, colocam alguns questionamentos importantes, que cabem aqui ser mencionados:

À educação cabe a tarefa de produção de "sujeitos" sociais: criação e reprodução... Podemos então perguntar: o que estamos produzindo? Que "sujeitos" estamos construindo? Mas o que entendemos por produção? Que tipo de produção queremos?..." (Eizirik \& Comerlato, 2004, p. 123). 
Por essa razão, comentam as autoras que seguir enfatizando os diversos problemas (violência, indisciplina, evasão escolar, dificuldades de aprendizagem, relações conturbadas na comunidade escolar como um todo, entre outras pautas) enfrentados hoje pela/na escola seria incorrer no risco de banalizar a discussão, pois comumente se fazem diagnósticos e buscam-se culpados. Entretanto, faz-se necessário ampliar o entendimento acerca de como se dão os processos de subjetivação no ambiente escolar; pois acredita-se que o estudo sobres os mesmos possa contribuir para uma reflexão sobre as relações de convivência na sociedade em geral.

Partindo do exposto, o presente artigo visa problematizar a questão da convivência escolar a partir da perspectiva da construção da subjetividade. Para tanto, foi realizada uma pesquisa bibliográfica a respeito do conceito de subjetividade, buscando possibilidades para ampliar a reflexão sobre a convivência escolar.

Compreendendo que a escola pública brasileira acolhe cerca de um quarto da população diariamente, oportunizando assim a interação entre pessoas dos mais diversos contextos e culturas, o presente estudo pretende possibilitar uma melhor compreensão acerca destas relações e de como as mesmas são afetadas pelo contexto sócio-político-econômico vigente, afinal, estas refletem diretamente nas relações da sociedade como um todo.

\section{Diferentes perspectivas acerca da construção da subjetividade}

No transcurso da história das sociedades, especialmente da Modernidade até então, as noções de sujeito e de subjetividade sofreram diversas transformações. Segundo Miranda (2005), o campo psi - psicologia, psiquiatria e psicanálise - produziu reflexões que contribuíram para restringir a subjetividade a aspectos interiores/internos do sujeito, sendo muitas vezes concebida como uma substância inata ao mesmo, desvinculando-o do meio que o circunda. Neste processo foi-se criando uma série de instrumentos e/ou dispositivos que serviram para mensurar/avaliar tal subjetividade. Entretanto, para atualidade tal conceito de subjetividade como substância interiorizada parece não mais contribuir para compreender as vivências dos sujeitos contemporâneos. Diante de infinitas redes de relações, uma infinidade de novos processos capazes de produzir diferentes modos de vida também surge. Por este motivo, faz-se necessário lançar mão de perspectivas multidisciplinares ou transdisciplinares, 
a fim de ampliar a compreensão deste conceito de subjetividade (Mancebo, 2002; Miranda, 2005).

O conceito de subjetividade tem se configurado de diferentes formas por diversas perspectivas teóricas. No entendimento de Leite e Dimenstein (2002, p. 16), subjetividade é "uma forma particular de se colocar, de ver e estar no mundo [mas] que não se reduz a uma dimensão individual". Ora ela fora concebida como uma dimensão psicológica, interiorizada e individualizada, não sujeita a influências e transformações históricas, sociais, políticas, econômicas ou tecnológicas, ora fora compreendida como produção do social, uma vez que determinantes sociais, de diferentes contextos culturais produzem diferentes subjetividades.

A partir dessa perspectiva individualista da subjetividade e com a influência do capitalismo e seus ideais de igualdade e liberdade, produziu-se uma concepção de que as pessoas eram (ou poderiam ser) livres e iguais (Mancebo, 1999). Concomitantemente a esse movimento, a Reforma Protestante que se deu na Idade Moderna também contribuiu para a construção de um indivíduo marcado por uma identidade e uma experiência fortemente individualizada; que ocorreu por meio de inúmeras ações como "abolição dos rituais, o repúdio ao sensualismo e à emoção, a desmagicização do mundo" (Mancebo, 2002, p. 101), resultando na compreensão de um ser humano "impessoal, racional e instrumental" (idem). Da mesma forma, em decorrência da revolução cientifica (séc. XVI e XVII), uma nova subjetividade começa a ser construída, esta agora embasada em um sujeito dicotômico, com razão e emoção bem definidas, onde a primeira deve sobrepujar a segunda. A partir de então, surge um sujeito racional e imparcial, preocupado com sua privacidade e zeloso para com sua interioridade, contexto que contribui para fomentar a concepção de uma subjetividade individualizada e universal, ou seja, o indivíduo como sendo o "centro microscópico do mundo, [uma] parte orgânica" (Mancebo, 2002, p. 102).

Neste contexto, a consolidação do capitalismo como modo de produção se tornou um marco fundamental quando se aborda o tema da subjetividade, na medida em que pressupõe mudanças não somente econômicas, mas também no plano da produção subjetiva com o desenvolvimento de um ideário de liberdade e igualdade. Estes ideários liberais não apenas consolidaram um novo modo de produção, senão que também forjaram a ideia de um sujeito autônomo, senhor de si mesmo (Figueiredo, 2007).

Deste modo, o liberalismo trouxe consigo algumas transformações no conceito de subjetividade a partir, principalmente, de dois momentos: em um primeiro, houve um “embaralhamento das esferas pública e privada" (Mancebo, 2002, p. 102) momento conhecido também como intimismo. No segundo, consolidou-se um "individualismo 
administrativo, tecnocrático e disciplinar" (idem). No primeiro, houve uma valorização do autocrescimento, onde o autodesenvolvimento individual regia completamente a conduta da vida pública - o que denotava a invasão do público pelo privado. Já no segundo movimento, o comportamento individual precisava ser planejado e controlado - é a chamada "era de domesticação dos corpos" - tão mencionada e contestada por Foucault (1987).

Neste contexto liberal, este sujeito autoconsciente e dotado de um absoluto domínio de si, influenciado por ideais românticos, começa a valorizar o autocrescimento e apregoar a inviolabilidade do individual, ou seja, o privado com suas virtuosidades e paixões passa a ter primazia sobre a vida pública competitiva, superficial e turbulenta dos grandes centros. A partir de então, os "valores e procedimentos da privacidade [...] passam a se elevar como organizadores e juízes da vida pública" (Figueiredo, 2007, p. 143). A decorrente perda dos limites entre as esferas pública e privada resultou em um certo esfumaçamento da cisão entre estes domínios, constituindo no seu conjunto o que vem sendo chamado de civilização intimista (Sennet, 1988).

Assim, ao mesmo tempo em que se forma uma subjetividade intimista, sob os ideais românticos do liberalismo, esta sofre influência de um ideário tecnocrático e disciplinar (marca característica da vida moderna) que resultou na construção de uma subjetividade onde os impulsos precisam ser contidos e as condutas modeladas (subjetividade aristocrática), contribuindo, consequentemente, para a segmentação e individualização do ser humano e suas relações. Contestando essa subjetividade concebida de forma individualizada, Foucault (1987) denunciou que o poder disciplinar presente no capitalismo inicial foi essencial para construção de um sujeito docilizado e restrito a um campo de saber, oculto dentro uma objetividade positivista. Sua crítica se deteve em desnaturalizar esta subjetividade pois, segundo ele, o sujeito é tanto produtor de conhecimento como também traspassado por ele, ou seja, são "formados e transformados mutuamente" (Miranda, 2005, p. 33).

Ao final dos anos 60, o mundo capitalista entrou em crise consolidando-se uma alternativa política, econômica, social, jurídica e cultural denominada de neoliberalismo. A existência deste dependeu de certas condições jurídicas, políticas e institucionais que foram implementadas e construídas de modo a abranger o desenvolvimento de formas artificialmente arranjadas ou impostas da conduta livre, empresarial e competitiva de indivíduos econômico-racionais. Sob esse conjunto de ideias e planos organizados, torna-se cada vez mais exigido dos indivíduos que o valor e as relações mercantis sejam introjetadas como padrão dominante de interpretação do mundo e que o mercado seja reconhecido como o âmbito onde, naturalmente, podem e devem se desenvolver como pessoas humanas. Portanto, 
a lógica do mercado aponta para uma função estruturadora das relações sociais e políticas na medida em que comporta um viés de interpretação dos homens marcado pelo utilitarismo individual (Mancebo, 1999, 2002; Peters, 1995).

No liberalismo clássico existia um apelo à razão sob a forma de um individualismo que favorecia um sujeito racional e cognoscente, como fonte de conhecimento, significação, autoridade moral e ação. Já no neoliberalismo, o que se postula é um comportamento utilitarista, ou seja, os próprios interesses do sujeito são reforçados, tanto no campo político quanto nos demais que envolvem a conduta humana, inclusive questões éticas passam a ser compreendidas como uma responsabilidade individual, conforme a busca de cada sujeito por sua felicidade e liberdade (Mancebo, 2000).

No entanto, tal comportamento, parecendo apregoar liberdade e igualdade (onde todos podem buscar igualmente a satisfação de seus desejos e de seu próprio bem-estar), resulta em desigualdade e exclusão. Isto porque, segundo a ideologia neoliberal, é a desigualdade que promove o equilíbrio, pois instiga a competição e consequentemente o desenvolvimento de uma determinada sociedade. Dessa forma, princípios que advogam o coletivo e o social sofrem deterioração, pois a ênfase se dá no comportamento que busca o sucesso individual a qualquer custo. Como consequência, tem-se um homem/mulher moderno (ou pós-moderno) "literalmente desligado do mundo, desinteressado" (Arendt, 1980 como citado em Mancebo, 2002, p. 104).

A partir do exposto, constata-se, a partir da Modernidade, a construção de uma subjetividade na qual os sujeitos são movidos por uma competitiva individualidade, sujeitando-se a uma homogeneização cultural. Esta, ao mesmo tempo em que valoriza o individual, também acaba massificando-o num comportamento passivo frente a uma interatividade social ilusória, isto em referência à globalização presente na sociedade contemporânea. Mancebo (2000) registra que os sujeitos, numa cultura de massa, são apreendidos

[...] em diversas situações de vida, inclusive em sua esfera estritamente privada; sugerem-lhe papéis, sentimentos e atitudes; tentam convencê-lo - através de suaves mensagens de entretenimento ou de informações alarmistas - quanto aos comportamentos sociais mais indicados ou não, para o alcance do reconhecimento social e quanto às identidades a serem incorporadas ou excluídas, para uma exitosa existência social (Mancebo, 2000, p. 59).

Portanto, nesse viés reflexivo, não se concebe a subjetividade como algo inerente ao interior do sujeito, ou mesmo algo totalmente individualizado ou universal, tendo em vista 
que esta perspectiva se volta para a uma concepção que exclui os aspectos históricos, sociais, políticos e econômicos que constroem este sujeito, como se estes não interferissem em seu cotidiano produzindo possíveis transformações. Pensadores como Foucault (1987), Deleuze (1992), Guattari e Rolnik (2005) contribuíram para refletir sobre uma subjetividade não tomada como uma essência/substância do indivíduo, mas como algo que vai se construindo e reconstruindo cotidianamente como resultado de práticas e de relações sociais. Segundo Guattari e Rolnik (2005) a subjetividade não está mais restrita a uma dimensão individual, estruturada no mundo privado; mas sim é um fato social que se constrói em meio a diferentes contextos sociais, políticos, econômicos, ideológicos, dentre outros, o que resulta na produção de diferentes subjetividades.

Por essa razão, Guattari e Rolnik (2005, p. 40) defendem o conceito de que "a subjetividade é essencialmente fabricada e modelada no registro do social", ou seja, não é da ordem do natural ou do universal. Isto significa que, para se compreendê-la, faz-se necessária uma compreensão para além do campo psi, adentrando os campos da sociologia, da economia, da arte, da filosofia e tantos outros. Tal conduta envolve transdisciplinaridade, ou seja, uma transversalidade de diferentes saberes.

Diante desta perspectiva processual de subjetivação, quaisquer práticas profisssionais e, neste caso, referindo-se ao contexto educacional/escolar, precisam voltar-se para o processo em que se dão as relações e posicionamentos. Sob este prisma abrem-se possibilidades de criação e recriação de subjetividades e o conceito dominante presente no capitalismo/liberalismo (de uma subjetividade homogênea e individual) se abre para a heterogeneidade/processualidade, rompendo com modelos de subjetividade mantenedores do status quo.

Rolnik (1997) explora os modos de subjetivação contemporâneos, problematizando-os à luz das influências nos campos da ética e da cultura. Em suas reflexões, a autora reitera a indissociabilidade entre cultura, ética e subjetividade, entendendo não haver existência de uma sem a influência das outras. Há presente neste processo diferentes perspectivas de criação-recriação; uma transversalidade de relações, conceitos que se entrelaçam influindo um sobre o outro. Corroborando tal concepção, Guattari e Rolnik (2005) reiteram que o conceito de produção de subjetividade não está atrelado a um sujeito como receptáculo de coisas que se interiorizam, mas a múltiplos componentes, por vezes inconscientes, que se entrecruzam no coletivo de várias espécies (sociais, econômicas, tecnológicas, mídia...). Neste campo de produção de subjetividades, este sujeito, tanto "acolhe os componentes de subjetivação em 
circulação, [quanto] também os emite, fazendo dessas trocas uma construção coletiva viva" (Mansano, 2009, p. 111).

Apreender como se dão esses processos de subjetivação na contemporaneidade permite que se compreenda as formas como se dão as relações entre os sujeitos, suas diferentes maneiras de convivência mútua. Estas relações interpessoais são permeadas pelos diferentes processos de subjetivações que se dão em um contexto de confluências múltiplas, que se interpõem umas sobre as outras, resultando em distintos modos de ação (política, ética, estética, cultural...). Acolher as diferenças no campo da subjetividade implica em concebê-la de forma viva, não apaziguada, mas ativa em transformações contínuas no/do social, em ações de resistência ao que se impõe no momento.

\section{A convivência escolar}

[...] escola é, por excelência, a instituição da alteridade e do estranhamento... (AQUINO, 2000, p. 39).

A escola contemporânea, como um espaço de convivência, está permeada por uma diversidade de sujeitos, cada um marcado pelo meio político-social-cultural em que estão inseridos. Tal diversidade manifesta como característica uma complexa rede de relações que se afetam, se inventam e reinventam cotidianamente, resultando em uma constante produção de subjetividade(s). Seguindo este raciocínio, convém refletir sobre como estas subjetividades se constroem na atualidade do contexto escolar (Cerezer, 2011; Mosé, 2015).

A concepção de um sujeito produzido por uma subjetividade individualizada terminou por isolá-lo de seus semelhantes em diferentes contextos. A premissa tão propagada na Modernidade era de que o homem poderia ser dono de si mesmo desde que a razão (e o conhecimento por ela adquirido e difundido) pudesse estar em evidência e primazia (Rocha, 2007, Heckert, Corona, Manzini, Machado \& Fardin, 2001). Segundo Mancebo (2002), ainda hoje se perpetua uma cultura individualista, mesmo sendo este ser humano construído histórica e socialmente. Deste modo, pode-se afirmar que a Modernidade assinalou o momento da hegemonização do ideário individualista que marcou profundamente as maneiras de ser sujeito até nossos dias, cultivando a produção de sujeitos voltados para o auto-interesse, para o sucesso individualizado e competitivo, que tornam esvaziadas e enfraquecidas as práticas e relações coletivas. 
O campo da Educação perpetuou, de certa forma, as mesmas concepções e premissas. O conhecimento foi compartimentado/fragmentado, assim como o sujeito; constituindo-se a escola como um dos mecanismos de serialização e disciplinamento. Mosé (2015) aponta estas fragmentações como um dos graves problemas escolares na atualidade e explana tal situação ao relatar alguns aspectos de como a vida escolar se organiza (conduta que vem se propagando há alguns séculos) - cada área de saber, como literatura, geometria, álgebra dentre outros, "são ministrados isoladamente" (Mosé, 2015, p. 49), sem se relacionarem mutuamente e nem com a vida.

Nesta linha de pensamento, Morin (2000, p. 40) enfatiza que, mesmo havendo um grande avanço em todas as áreas de conhecimentos no último século, este progresso fícou disperso em disciplinas "hiperespecializadas, fechadas em si mesmas"; estendendo-se inclusive para as relações humanas, tornando-se estas isoladas e descontextualizadas com pouco ou nenhum espaço de convivência. Morin (2000), ressaltando a complexidade deste humano e das relações que o constroem, denuncia essa fragmentação presente na educação bem como no campo escolar que acaba impedindo

[...] tanto a percepção do global (que ela fragmenta em parcelas), quanto do essencial (que ela dissolve). Impede até mesmo tratar corretamente os problemas particulares, que só podem ser propostos e pensados em seu contexto (Morin, 2000, p. 41).

Esse modo de ensinar/aprender fragmentado é visto por Mosé (2015) como um convite à alienação, prejudicando não apenas o desenvolvimento cognitivo dos(as) alunos(as) senão que também "as relações humanas, a prática da justiça social, o exercício da cidadania" aumentando o "grau de angústia e solidão" (Mosé, 2015, p. 51) que acaba resultando em mais isolamento e consumismo - características de uma subjetividade capitalística, tão promulgada por Guattari (2005).

O ser humano sendo construído de forma tão fragmentada, acaba se desvinculando cada vez mais das questões sociais, não conseguindo articular-se em várias ações e/ou pensamentos; acaba não conseguindo mais compreender a multiplicidade e multidimensionalidade dos fenômenos que o cercam. Tal situação gera, consequentemente, sujeitos facilmente manipulados e crentes de que são completamente impotentes para transformar-se e transformar o mundo que os cerca.

As dificuldades em se relacionar com o outro talvez sejam decorrentes de tal quadro desenhado até o momento. Se as subjetividades são construídas socialmente; os sujeitos não estão isolados no/do mundo que o cerca. No entanto, uma escola tomada como um espaço 
fragmentado, acaba contribuindo para gerar indivíduos ainda mais desconectados com o todo e com o outro. A escola parece estar ensinando saberes de muitas coisas em seus respectivos campos de atuação, mas não se mostra capaz de integrá-los entre si e com a vida social, profissional, afetiva. Talvez a escola, mesmo sendo concebida como um espaço de socialização, esteja desaprendendo a socializar ou, no limite, ensinando a dessocializar.

Dessa forma, percebe-se que o ambiente escolar tem se tornado um espaço conflitante de relações, "um campo de pequenas batalhas civis", segundo Aquino (1998, p. 8). A convivência dentro do espaço da escola parece ser uma reprodução das relações extraescolares, mas o será mesmo? O mesmo autor salienta que há um entrelaçamento entre as ações tanto da instituição-escola quanto da sociedade na qual está inserida. As relações escolares têm sofrido as consequências de uma sociedade instável, que vivencia mudanças cada vez mais rápidas em diversos aspectos. Mudanças diretamente relacionadas a transformações de paradigmas onde caem "a concepção de um mundo e de uma sociedade previsíveis e regulados [passando] a valorizar o incessante fluxo das mudanças ao ritmo da evolução do próprio mercado" (Estevão, 2008, p. 505).

Em outro de seus trabalhos, Aquino (2000) retrata que, embora algumas transformações sejam conotadas como positivas (pois atualmente o mundo, aparentemente, é mais flexível), elas acabaram por provocar certas rachaduras nas relações humanas que resultaram em uma crise de dimensão ética da vida em sociedade. Mosé (2015) comenta que o modelo educacional vigente e a escola atual vivem um cenário de exaustão, não conseguindo satisfazer ninguém, pois esta instabilidade nasce diante da incompatibilidade entre a própria escola e as crescentes inovações tecnológicas. O que se oferece na escola hoje, seja em nível de conhecimento ou em nível de relações já não é compatível com as demandas da sociedade como um todo.

Refletindo sobre a complexidade das relações, Morin (2000) segue salientando que o ser humano é um ser múltiplo que precisa ser entendido com um todo único e diverso ao mesmo tempo. A dificuldade em se apreender a realidade de tal diversidade e singularidade é o que pode conduzir o mesmo a um estado de barbárie. Segundo o autor, apreender a complexidade do humano e suas relações implica ampliar a visão para um todo cujas partes são inseparáveis entre si; o que significa, contextualizado para o ambiente escolar/educacional, desenvolver uma nova forma de ver, sentir, querer, conviver e conhecer para além da lógica excludente presente no mesmo. Segundo o autor, existe uma falta de compreensão do/pelo outro na sociedade atual, sendo, portanto, finalidade da educação ensinar tanto a pensar quanto a viver juntos. 
A escola, como instituição social, serve então como mediadora entre a pessoa/criança e a sociedade, portanto, não pode viver isolada da realidade social que a cerca. Reflexões acerca desta sua finalidade social precisam ser repensadas entendendo que a escola inevitavelmente responde às necessidades de um determinado momento histórico, por isso precisa conhecer os valores e modelos que permeiam/regem o funcionamento da sociedade na qual está inserida (Bock, Furtado \& Teixeira, 2008).

Partindo da reflexão de que a educação escolar é um instrumento de transformação intelectual e existencial, entende-se que a escola deve ser este lugar onde o(a) estudante não apenas adquira conhecimento, mas também consiga adquirir ou construir ferramentas importantes para atuar na sociedade como um(a) cidadão(ã) consciente de seus direitos e deveres. Mosé (2015) comenta que educar é um processo complexo, pois as pessoas são complexas, assim como as relações entre si e, dessa maneira, se faz necessária uma compreensão não linear de todo esse processo, respeitando e valorizando cada ator envolvido (gestores, professores, alunos, famílias, comunidade), articulando ações que contemplem a vontade de todos e a convivência democrática entre os mesmos.

Assim sendo, a escola precisa posicionar-se de forma crítica responsabilizando-se por seu papel de mudança e transformação desta sociedade. Decorrente disto, é vital que se indague sobre quais necessidades são atendidas pelos conhecimentos que propaga, quais valores, modelos e regras que perpetua e por quê. Vive-se na atualidade um sentimento de impotência frente à velocidade acelerada das mudanças e o sujeito deste contexto vive isolado e enredado em redes de competitividade que, segundo Rocha (2007), geram uma desafeição pelo coletivo em movimento e uma consequente precarização da cidadania ativa. Neste sentido, Mosé (2015) reforça o conceito de que a escola precisa ser um espaço vivo, tanto de produção de saberes quanto de convivência ética e democrática, caso contrário corre o grave risco de tornar-se obsoleta em suas funções.

A convivência escolar, as relações entre seus diferentes atores, tornam-se indispensáveis no sentido de buscar e construir as transformações sociais necessárias na atualidade. Entretanto, Mosé (2015, p. 22) comenta que há no contexto educacional atual uma “alarmante imaturidade política e social". Isto porque

nunca fomos tão incapazes de conviver, tão incapazes de seguir um acordo, tão incapazes de viver. Odiamos as regras, buscamos um prazer cada vez mais descartável e imediatista, matamos o que não temos coragem de transformar. Fazemos altíssimo uso de drogas lícitas e ilícitas, de medicação psiquiátrica; acessamos a tecnologia 
contra o tempo, contra a morte contra o sofrimento, mas desaprendemos a acessar a vida e estamos desaprendendo a reelaborar nossa dor em arte (Mosé, 2015, p. 22).

Diante da fragilidade das relações na sociedade contemporânea são frequentes ações de inclusão e exclusão. Inclusão daqueles(as) que se adequam ao sistema e exclusão daqueles(as) que resistem ou se contrapõem. Segundo Mosé (2015), a escola ainda é um dos primeiros mecanismos de inclusão/exclusão nas vivências subjetivas; primeiro porque se a concebe, por vezes, isolada da sociedade, fechada em seus muros e detendo o conhecimento; segundo porque não costuma se responsabilizar pelo fracasso de seus alunos, jogando toda a responsabilidade sobre eles próprios. Dupla exclusão que a escola mobiliza: distanciando-se da sociedade e isolando seus estudantes na culpa individualizada por seus fracassos escolares.

Diante de tal situação, formas de resistência se manifestam, reclamando para si o direito de acessar alguma inclusão. Algumas formas resistência - por vezes a indisciplina, o baixo rendimento de seus(suas) estudantes ou mesmo agressividade/violência - podem ser sinalizadores de algo não está equânime nas relações que ali se constroem. Aquino (2000) comenta que há um novo sujeito histórico e social na contemporaneidade, com outras demandas, valores e hábitos distintos daquele concebido há cerca de 50 anos atrás. Diante de tal fato, a própria escola, enquanto instituição, não consegue aglutinar tais sujeitos com suas diferenças e necessidades, gerando a exclusão dos mesmos.

Pensar em uma convivência mais democrática na escola implica em "construir experiências democráticas" (Marcon, 2015, p. 391) entre sujeitos diferentes, com posicionamentos diferentes que por vezes podem gerar conflitos. Deste modo, entende-se que a escola precisa educar para democracia para então estabelecer uma convivência democrática.

Sem uma predisposição do coletivo em participar de todas as instâncias e espaços de discussão e formulação de políticas no âmbito da escola, não há como falar em democracia de fato (Marcon, 2015, p. 392).

Este modo de conviver na escola e, por conseguinte, na sociedade como um todo é um desafio no qual se torna imprescindível tanto estimular o pensar na diversidade do coletivo, como atentar para não fomentar ações excludentes de grupos, classes ou organizações. Para tanto, toda comunidade escolar precisa contribuir para construção de "sujeitos ativos, pensantes e participativos" (Marcon, 2015, p. 393).

\section{Considerações finais}


Por meio da breve contextualização histórica a respeito dos processos de construção de subjetividades e da instituição escolar, foi possível entender que esta se configura como um espaço não somente de transmissão de conhecimentos objetivos a partir das disciplinas, mas também como um local de socialização no qual todos os sujeitos envolvidos são subjetivados.

Assim, compreendeu-se que escola, enquanto instituição de ensino, foi se estabelecendo ao longo da história como um lugar de preparação para vida e também como um espaço de socialização. Acolhendo pessoas das mais diversas culturas e contextos, têm instituído, por meio de suas práticas, valores e comportamentos que maiormente visam satisfazer o mercado atual, que separa, divide e hierarquiza. Neste contexto, as relações se tornam competitivas, imperando um individualismo onde cada um é por si e onde os valores da coletividade ficam reduzidos e/ou sumariamente enfraquecidos.

Pôde-se perceber que a fragmentação da escola impede o desenvolvimento de uma percepção global acarretando um aumento no grau de angústia, solidão, isolamento e consumismo, fatores característicos da subjetividade denominada capitalística. Afinal, em decorrência da fragilidade das relações, na convivência escolar, são frequentes ações de exclusão, desrespeito e resistência. Portanto, a necessidade de pensar na convivência democrática se torna fundamental para a construção de sujeitos ativos e cada vez mais capazes de levar em conta os valores da coletividade.

Compreender as relações humanas não é uma tarefa simples, pode-se perceber, ainda mais considerando-se que estas se engendram permeadas por construções de subjetividades pautadas num individualismo vestido de liberdade e igualdade ilusórias. A escola, como mediadora social, precisa refletir e repensar suas práticas a fim de colaborar para construção de uma sociedade solidária guiada pela alteridade. Desfragmentar-se para ver-se por inteira, compreendendo que desconstruir seus dispositivos individualizantes e normatizadores, pode resultar na adoção de práticas que corroborem para construção de um espaço de liberdade, onde subjetividades podem se construir e reconstruir pautadas em valores coletivos e não simplesmente individualizantes.

Talvez trilhar esse caminho, segundo Eizirik e Comerlato (2004), suscite a busca por interesses comuns, onde os objetivos individuais se articulam com os objetivos sociais, e, segundo as palavras das autoras: "podem ser passos para a construção da democracia, fundada nos direitos de cada um para com todos e de todos para com cada um" (Eizirik \& Comerlato, 2004, p. 131). 


\section{Referências}

Aquino, J. G. (1998). A violência escolar e a crise da autoridade docente. Cadernos Cedes, 19 (47), p. 7-19.

Aquino, J. G. (2000). Do Cotidiano Escolar. Ensaios sobre a ética e seus avessos. São Paulo: Summus.

Bock, A. M. B., Furtado, O. \& Teixeira, M. L. T. (2008). A Escola. In: Bock, A. M. B.; Furtado, O. \& Teixeira, M. L. T. Psicologias: uma introdução ao estudo de psicologia (14a ed, Cap. 18, pp. 266-281). São Paulo: Saraiva.

Cerezer, C. (2011). Autoridade e mal-estar do educador. São Paulo: Zagadoni.

Deleuze, G. (1992). Conversações (1972-1990). Rio de Janeiro: Ed. 34.

Eizirik, M. F. \& Comerlato, D. (2004). A escola (in)visivel: jogos de poder, saber, verdade ( $2 \mathrm{a}$ ed). Porto Alegre: Editora da UFRGS.

Estêvão, C. V. (2008). Educação, conflito e convivência democrática. Ensaio: aval. pol. públ. Educ., 16 (61), p. 503-514.

Figueiredo, L. C. M. (2007). A invenção do psicológico: quatro séculos de subjetivação (1500-1900) (7a ed). São Paulo: Escuta.

Foucault, M. (1997). Vigiar e punir: o nascimento da prisão (22a ed.). Petrópolis: Vozes.

Guattari, F. \& Rolnik, S. (2005). Micropolitica: cartografias do desejo (7a ed). Petrópolis, RJ: Vozes.

Heckert, A. L. C., Corona, C. R., Manzini, J. L., Machado, R. R. B., Fardin, V. L. (2001). A escola como espaço de invenção. In: Jacó-Vilela, A. M., Cerezzo, A. C., Rodrigues, H. B. C. 
Clio-Psyché Hoje: fazeres e dizeres psi na história do Brasil (pp. 239-250). Rio de Janeiro: Relume Dumará/FAPERJ.

Leite, J. F. \& Dimenstein, M. (2002). Mal-estar na psicologia: a insurreição da subjetividade. Revista Subjetividades, 2 (2), p. 9-26.

Mancebo, D. (1999). Modernidade e produção de subjetividades: gênese e possibilidades atuais (Tese apresentada em concurso para professora titular). Universidade do Estado do Rio de Janeiro, 1999.

Mancebo, D. (2000). Globalização e efeitos de subjetivação. Logos, 7 (1), p. 57-62.

Mancebo, D. (2002). Modernidade e produção de subjetividades: breve percurso histórico. Psicologia: ciência e profissão, 22 (1), p. 100-111.

Mansano, S. R. V. (2009). Sujeito, subjetividade e modos de subjetivação na contemporaneidade. Revista de Psicologia da UNESP, 8 (2), p. 110-117.

Marcon, T. (2015). Educação e democracia: formação política para a convivência em uma sociedade plural. Roteiro, 40 (2), p. 377-394.

Miranda, L. L. (2005). Subjetividade: a (des)construção de um conceito. In: Souza, S. J. (org). Subjetividade em questão: a infância como crítica da cultura (2a ed, pp. 29-46). Rio de Janeiro: 7Letras.

Morin, E. (2000). Os sete saberes necessários à Educação do Futuro (2a ed). São Paulo: Cortez, 2000.

Mosé, V. (2015). A escola e os desafios contemporâneos (4a ed). Rio de Janeiro: Civilização Brasileira.

Peters, M. (1995). Governamentalidade neoliberal e educação. In: SILVA, T. T. (Org.). $O$ sujeito da educação: estudos foucaultianos (2a ed). Petrópolis: Vozes. 
Rocha, M. L. (2007). Inclusão ou exclusão? Produção de subjetividade nas práticas de formação. Psicologia em estudo, 13 (3), p. 477-484.

Rolnik, S. (1997). Uma insólita viagem à subjetividade. Fronteiras com a ética e a cultura. In: Lins, D. (Org.). Cultura e Subjetividade: saberes nômades. (p. 25-35). Campinas: Papirus.

Sennett, R. (1988). O declínio do homem público. São Paulo: Cia das Letras.

\section{Porcentagem de contribuição de cada autor no manuscrito}

Elysangela Koglin Ulo Limachi - 50\%

Isabelle Rittes Nass - 10\%

Marcele Pereira da Rosa Zucolotto - 40\% 